\title{
Zeta Potential of Beta Zeolites: Influence of Structure, Acidity, pH, Temperature and Concentration
}

\author{
Xuan Liu ${ }^{1}$, Päivi Mäki-Arvela ${ }^{1}$, Atte Aho ${ }^{1}$, Zuzana Vajglova ${ }^{1}$, Vladimir M. Gun'ko ${ }^{2}$ (D), \\ Ivo Heinmaa ${ }^{3}$, Narendra Kumar ${ }^{1}$, Kari Eränen ${ }^{1}$, Tapio Salmi ${ }^{1}$ and Dmitry Yu. Murzin ${ }^{1, *}$ \\ 1 Laboratory of Industrial Chemistry and Reaction Engineering, Faculty of Science and Engineering, \\ Johan Gadolin Process Chemistry Centre, Åbo Akademi University, FI-20500 Turku/ ̊bo, Finland; \\ xuan.liu@abo.fi (X.L.); pmakiarv@abo.fi (P.M.-A.); atte.aho@abo.fi (A.A.); zuzana.vajglova@abo.fi (Z.V.); \\ nkumar@abo.fi (N.K.); keranen@abo.fi (K.E.); tsalmi@abo.fi (T.S.) \\ 2 Chuiko Institute of Surface Chemistry, National Academy of Sciences of Ukraine, 03164 Kiev, Ukraine; \\ vlad_gunko@ukr.net \\ 3 National Institute of Chemical Physics and Biophysics, Akadeemia tee 23, 12618 Tallinn, Estonia; \\ ivo.heinmaa@kbfi.ee \\ * Correspondence: dmurzin@abo.fi; Tel.: +358-2215-4985
}

Received: 11 March 2018; Accepted: 13 April 2018; Published: 18 April 2018

\begin{abstract}
Measurements of the zeta potential of solid heterogeneous supports are important for preparation of metal supported catalysts and for shaping zeolites into extrudates. In the current work, different types of heterogeneous support materials such as $\mathrm{SiO}_{2}, \mathrm{Al}_{2} \mathrm{O}_{3}$, and a range of beta zeolites of different silica- to-alumina ratio were analysed. It was observed that parameters such as temperature, $\mathrm{pH}$ and acidity significantly affect the zeta potential. In several instances, depending on the materials' acidity and microstructure, maxima in zeta potential were observed. The solid materials were thoroughly characterized using XRD, SEM, EDX, TEM, nitrogen physisorption, Al-NMR and FTIR with pyridine before zeta potential measurements.
\end{abstract}

Keywords: zeolites; beta; zeta potential

\section{Introduction}

The immense importance of catalysis in the chemical industry is manifested by the fact that roughly $85-90 \%$ of all chemical products have seen a (heterogeneous) catalyst during the course of their production. An important class of industrially applied heterogeneous catalysts includes various supported metal and metal or metalloid oxides, which activity and selectivity strongly depend on several factors, such as particle morphology and structure as well as support properties [1]. There are several methods to deposit an active phase on a support, including impregnation, deposition precipitation, strong electrostatic adsorption or colloidal stabilization of metal nanoparticles. In those methods, the surface properties are of importance to obtain the metal particles with appropriate cluster sizes. In fact, the metal particle size and its distribution are one of the most crucial properties of the catalysts. A relationship between the metal cluster size and relative difference between the points of zero charge $\left(\mathrm{pzc}, \mathrm{pH}_{\mathrm{pzc}}\right)$ or isoelectric point $\left(\mathrm{pH}_{\mathrm{IEP}}\right)$ and $\mathrm{pH}$ of deposition was established [2].

As well-known $\zeta$-potential is among the most important characteristics of colloidal systems being defined as the electric potential at the slipping plane which separates a mobile fluid from the fluid that remains attached to the surface [3-5]. Subsequently rheological behavior of molding masses influences the textural properties of extrudates, as mentioned by Foundas et al. [5]. Zeta potential gives information about the surface charge (including an immobile part of electric double layer, EDL) of the material being important not only for such applications as preparation of metal supported catalysts [1], but also 
for catalyst shaping [6,7]. For example, a correlation has been found between the difference in solution $\mathrm{pH}$, zeolite $\mathrm{pH}_{\mathrm{IEP}}$ and the relative particle attrition index measured in the Davison jet cap for FCC (fluid catalytic cracking) catalyst [8].

The influence of a binder on catalyst shaping and zeta potential was also considered in [7] linking zeta potential to the rheology of catalyst shaping [3-5]. The yield stress depends on the zeta potential through a complex relationship. An example of the influence of zeta potential on catalyst shaping was provided by Devyatkov et al. [7]. Shaping of zirconia together with the alumina binder was done at several values of $\mathrm{pH}$. It was found that a decrease in $\mathrm{pH}$ favors a smoother flow and gives defect-free catalyst extrudates. At the same time the decrease in $\mathrm{pH}$ elevated the zeta potential negatively influencing the mechanical stability of extrudates. When zeta potential is far from zero the shear stress is lower making the shaping mass behavior more like a Newtonian-type. In some extreme cases this can result in so-called green bodies not capable of retaining their shapes. The pore structure of the formed zirconia-alumina extrudates [7] was unaffected by rheological parameters when the zeta potential is close to zero, while significant deviations from zero afforded more uniform pore size distributions. All these data show that the influence of surface properties and rheology should be taken into account while selecting the optimum zeta potential values for catalyst shaping.

The present paper deals with zeta potential measurements of catalyst supports such as silica and alumina. Additionally, a substantial effort was put on understanding zeta potential behavior of zeolites of different morphology, structure and acidity. Zeolites and metal-modified zeolites are widely used in industry, since they exhibit shape selectivity, their acidity can be tuned without changing the morphology and furthermore they can be easily regenerated and reused. Although, several publications can be found on zeta potential and surface charge measurements of aluminosilicates and zeolites [6-31], there is still a need for systematic information on the effect of support acidity [9] or temperature on the zeta potential.

Zeta potential measurements have been reported for several types of aluminosilicates, such as mica [10,11], muscovite [12], montmorillonite [13-15], zeolite Y [16], ZSM-5 [6], beta-zeolite [6,9], silicalite [9,17], bentonite [18], chlorite [19], kaolinite [13,20-23], kaolin [24], pyrophyllite, [25] and albite [26]. Additionally, electrophoretic surface charge was reported for attapulgite [27], electrophoretic mobility for montmorillonite [28], palygorskite [29] and bentonite [30], as well as surface charge for montmorillonite [31] and natural zeolite [32]. Typically, zeta potential decreases with increasing $\mathrm{pH}$ for such aluminosilicates as mica [10], chlorite [19], kaolinite [22], kaolin [24], pyrophyllite [25], albite [27], bentonite [18], and ZSM-5 [6]. Analogously, the electrophoretic mobility decreases with increasing $\mathrm{pH}$ for palygorskite [31]. There are also reports on the unusual behavior of zeta potential curves as a function of $\mathrm{pH}$ giving maxima [12,33] or irregular patterns [30].

A detailed description regarding determination of the zeta potential and particle sizes of pristine $\mathrm{SiO}_{2}, \mathrm{Al}_{2} \mathrm{O}_{3}$, and $\mathrm{TiO}_{2}$ has been provided in a review [34]. Modification of the pristine single oxide or mixed oxides by transition or noble metals can influence the zeta potential values [15]. The aim of the present research was to study the influence of $\mathrm{pH}$ on the zeta potential of the $\mathrm{H}$ form of $\mathrm{H}$-beta zeolites with different $\mathrm{SiO}_{2} / \mathrm{Al}_{2} \mathrm{O}_{3}$ ratios. Conventional supports such as alumina and silica were used for reference purposes. Furthermore, the influence of temperature and concentration of tested catalysts in aqueous suspensions was also investigated. It should be noted that addition of any indifferent electrolyte (e.g., metal salts) strongly affects the electric double layer (EDL). Upon comparison of the electrophoretic behavior of different solids, a poorly controlled factor appears if the salinity of the suspension is not zero. In particular, an important factor which can influence in principle isoelectric point (IEP) is ionic strength, as IEP can change in the presence of such electrolytes as for example $\mathrm{KOH}$ [35]. This is important when the added electrolyte has a special affinity to the surface. Otherwise, the effect of the presence of electrolyte on IEP can be relatively minor, as evidenced for example for zeta potential of montmorillonite not changing the qualitative shape of the zeta potential curve as a function of $\mathrm{pH}$ [35]. To clarify this issue zeta potential measurements in this work were done predominantly in distilled water, while in some case the salinity of the suspensions was deviating from zero increasing the ionic strength of suspensions. 
According to the best of our knowledge, there is only one publication on zeta potential studies for beta zeolites with varying $\mathrm{SiO}_{2} / \mathrm{Al}_{2} \mathrm{O}_{3}$ ratio [9]. It is also noteworthy to mention here that the research results reported are the first in-depth study of the influence of important parameters such as structure of support, $\mathrm{pH}$, temperature, acidity and concentration on the values of zeta potential.

\section{Results}

\subsection{XRD Results}

XRD measurements were performed to confirm the structures of zeolites used. The diffractogram of H-Beta shows clearly typical $2 \theta$ peaks of beta zeolite at $22.4^{\circ}$ and $7.6^{\circ}$ (Figure 1) [36] with a high degree of crystallinity.

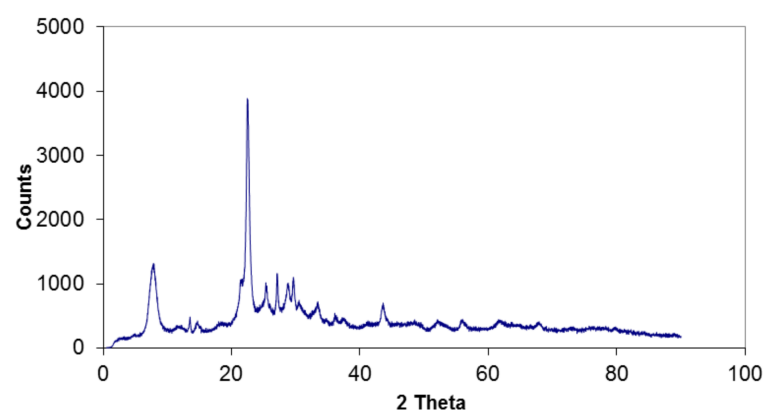

Figure 1. X-ray powder diffraction pattern of H-Beta-25 zeolite.

\subsection{Specific Surface Area and Morphology of Zeolites}

Specific surface areas, $S_{\mathrm{BET}}$ (Table 1) of zeolites were determined from nitrogen adsorption isotherms. The values of $S_{\text {BET }}$ of H-beta zeolites varied between $664 \mathrm{~m}^{2} / \mathrm{g}$ and $807 \mathrm{~m}^{2} / \mathrm{g}$ and appeared to not be correlated with the $\mathrm{SiO}_{2} / \mathrm{Al}_{2} \mathrm{O}_{3}$ ratio.

Table 1. Specific surface areas of catalysts studied for zeta potential measurements.

\begin{tabular}{lcc}
\hline Catalysts & Specific Surface Area, $\left(\mathbf{m}^{2} / \mathbf{g}\right)$ & Ref. \\
\hline H-Beta-25 & 807 & {$[37]$} \\
H-Beta-150 & 664 & {$[37]$} \\
H-Beta-300 & 805 & {$[37]$} \\
\hline
\end{tabular}

SEM image of H-beta zeolites are shown in Figures 2 and 3. The morphology of H-beta-150 was similar to that seen in Figure 2.

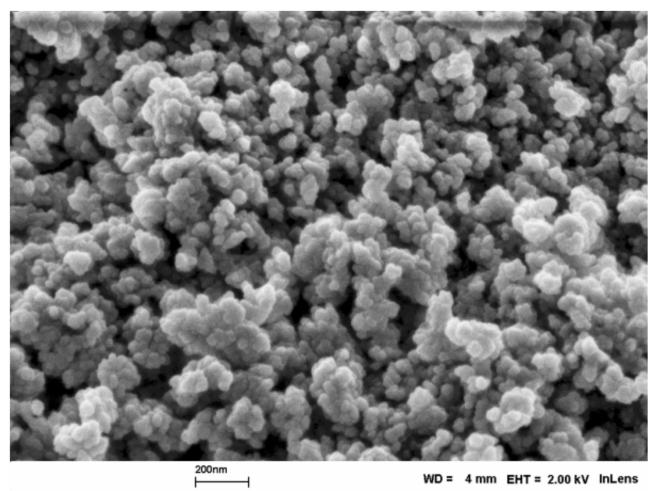

Figure 2. Scanning electron micrograph H-beta-25. 


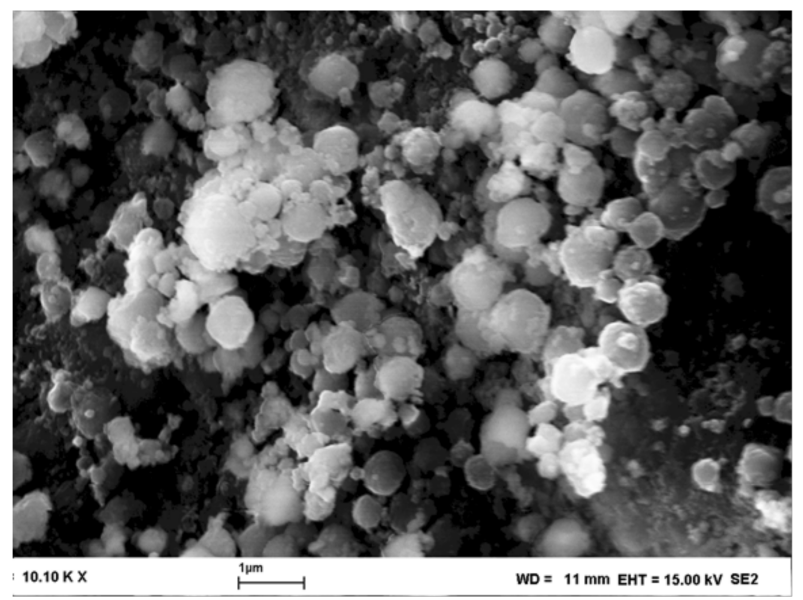

Figure 3. Scanning electron micrograph H-beta-300.

The particles of H-beta zeolite are round shaped particles similar to the results reported in [38]. The size of H-beta- 300 varied in the range of $0.4-1 \mu \mathrm{m}$, whereas the particles of H-beta- 25 were much smaller, being in the range of $70-140 \mathrm{~nm}$.

\subsection{Acidity of Zeolites}

The total amounts of Brønsted and Lewis acid sites in H-beta-300 are only $24 \%$ and $27 \%$ of those present in H-beta-25 (Table 2).

Table 2. Determination of Brønsted and Lewis acid sites in H-beta zeolite catalysts.

\begin{tabular}{ccccccccc}
\hline \multirow{2}{*}{ Catalysts } & \multicolumn{3}{c}{ Brønsted Acidity, $(\boldsymbol{\mu m o l} / \mathbf{g})$} & \multicolumn{3}{c}{ Lewis Acidity, $(\boldsymbol{\mu m o l} / \mathrm{g})$} & \multirow{2}{*}{ Ref. } \\
\cline { 2 - 6 } & $\mathbf{2 5 0}{ }^{\circ} \mathbf{C}$ & $\mathbf{3 5 0}{ }^{\circ} \mathbf{C}$ & $\mathbf{4 5 0}{ }^{\circ} \mathbf{C}$ & $\mathbf{2 5 0}{ }^{\circ} \mathbf{C}$ & $\mathbf{3 5 0}{ }^{\circ} \mathbf{C}$ & $\mathbf{4 5 0}{ }^{\circ} \mathbf{C}$ & \\
\hline H-beta-25 & 219 & 187 & 125 & 82 & 43 & 25 & {$[39]$} \\
H-beta-150 & 176 & 161 & 72 & 43 & 23 & 10 & {$[37]$} \\
H-beta-300 & 54 & 49 & 23 & 28 & 9 & 4 & {$[39]$} \\
\hline
\end{tabular}

Acidity decreases as follows: H-beta-25 > H-beta- $150>>$ H-beta-300. According to ${ }^{27}$ Al MAS NMR spectra the total acidity of H-beta 25 and H-beta-150 are close to each other (Table 3).

Table 3. Line intensities in ${ }^{27}$ Al-MAS NMR spectra from H-beta-25, H-beta-150, H-beta-300 zeolites.

\begin{tabular}{lcccccccc}
\hline Catalysts & Al(IV)a & Al(IV)b & Sum Al(IV) & Al(V) & Al(VI)a & Al(VI)b & Sum Al(VI) & Sum \\
\hline H-beta-25 & 1.9 & 15.5 & 17.4 & 6.4 & 0.9 & 11.2 & 12.1 & 35.9 \\
H-beta-150 & 3.8 & 15.1 & 18.9 & 6.8 & 0.5 & 11.9 & 12,4 & 38.2 \\
H-beta-300 & 1.5 & 2.7 & 4.2 & 2.9 & 0.1 & 1.8 & 1.9 & 9.0 \\
\hline
\end{tabular}

$\mathrm{Al}(\mathrm{IV}) \mathrm{a}$ and $\mathrm{Al}(\mathrm{IV}) \mathrm{b}$ denote aluminum in tetrahedral sites at 58 and $55 \mathrm{ppm}$, respectively.

Extra framework $\mathrm{Al}$ species appear about $0 \mathrm{ppm}$ and exhibit Lewis acidity, whereas framework $\mathrm{Al}$ species with Brønsted acidity display a signal at $60 \mathrm{ppm}$ (Figure 4), which is linked to the O-coordination numbers of $\mathrm{Al}$ atoms [40]. Generally, the acidity of H-beta-25 and H-beta-150 is much higher than that measured for H-beta-300. This result follows from both pyridine desorption and analysis of ${ }^{27} \mathrm{Al}-\mathrm{MAS}$ NMR spectra. 


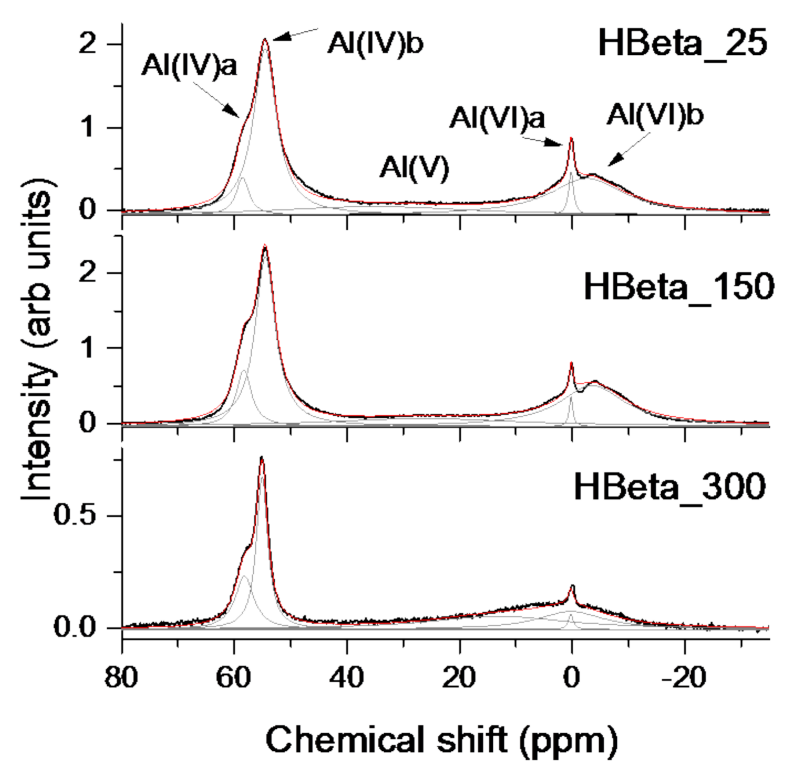

Figure 4. ${ }^{27}$ Al-MAS NMR results from H-beta-25, H-beta-150, H-Beta-300 materials. Gray lines show the components of the spectra.

\subsection{Zeta Potential of Oxides and Zeolites}

Zeta potential as a function of $\mathrm{pH}$ was determined for alumina, silica and $\mathrm{H}-$ beta. The main variables were sample concentration, $\mathrm{SiO}_{2} / \mathrm{Al}_{2} \mathrm{O}_{3}$ ratio and temperature.

\subsubsection{Zeta Potential for Individual Oxides}

Preliminary measurements of zeta potential were made for alumina and silica to check the data validity (Figure 5) [1]. Generally, under acidic $\mathrm{pH}$ the oxide surfaces are positively charged due to protonation of surface hydroxyl groups, whereas at high $\mathrm{pH}$ values deprotonation of terminal silanol and bridged oxygen for alumina occurs leading to negative surface charges. Zeta potential curves typically drop down with increasing $\mathrm{pH}$ (Figure 5). The IEP for silica and alumina were 3.9 and 8.8, respectively, being analogous to those reported in the literature [41]. Somewhat lower values for IEP (ca. 3) were also reported in the literature for silica [42].

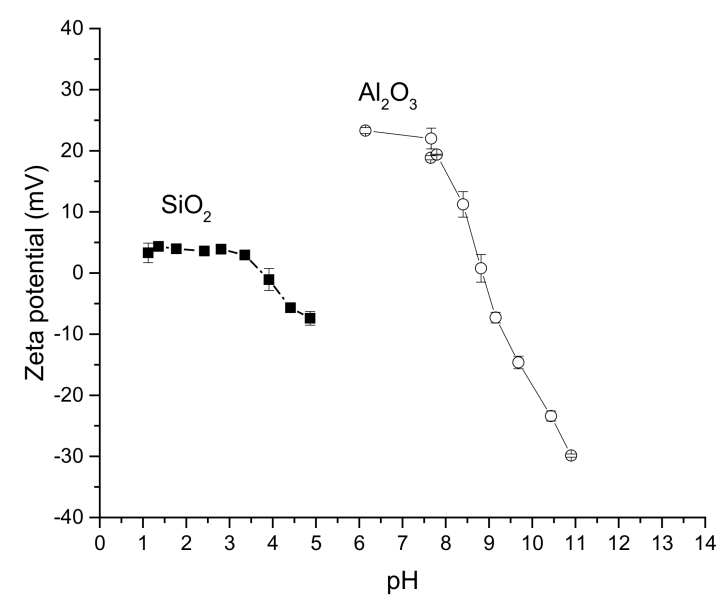

Figure 5. Zeta potential as a function of $\mathrm{pH}$ for $\mathrm{Al}_{2} \mathrm{O}_{3}$ (La Roche Versal alumina GL25) and for $\mathrm{SiO}_{2}$ (Merck silica gel Si-60). Conditions: $2 \mathrm{mg} / \mathrm{mL}, 25^{\circ} \mathrm{C}$. 
On the other hand, the zeta potential curve for a physical mixture of $\mathrm{SiO}_{2}$ (Merck, Darmstadt, Germany) and $\mathrm{Al}_{2} \mathrm{O}_{3}$ (UOP, Des Plaines, IL, USA) with the molar ratio of 25:1 resembled that of alumina, even if the alumina content in the mixture is rather low (Figure 6).

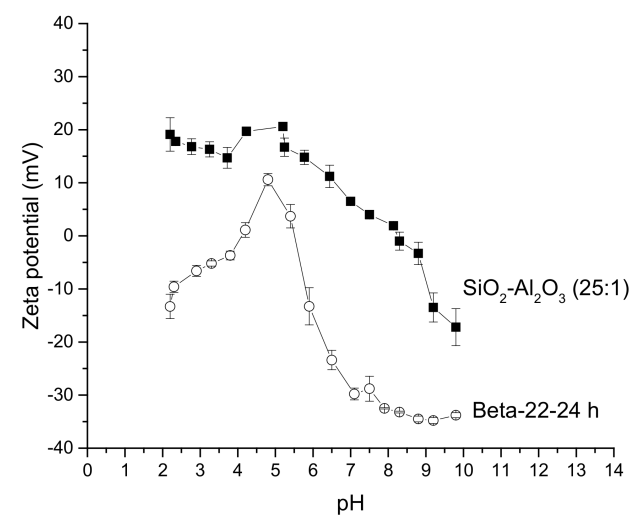

Figure 6. Zeta potential curves as a function of $\mathrm{pH}$ for a physical mixture $\mathrm{SiO}_{2}-\mathrm{Al}_{2} \mathrm{O}_{3}$ with a molar ratio of 25:1 and for an amorphous zeolite mixture with silica to alumina ratio of 22 aiming for Beta zeolite structure, synthesized for $24 \mathrm{~h}$. Conditions: $2 \mathrm{mg} / \mathrm{mL}, 25^{\circ} \mathrm{C}$.

The value of $\mathrm{IEP}_{\mathrm{C}}$ for this silica-alumina mixture was 8.1, whereas for pure $\mathrm{SiO}_{2}$ (Merck) and $\mathrm{Al}_{2} \mathrm{O}_{3}$ (UOP) it was respectively 3.8 and ca. 8.4. H-Beta-zeolite with silica to alumina ratio of 22 and synthesis time of only $24 \mathrm{~h}$ exhibited a maximum at $\mathrm{pH} 5$ (Figure 6). The values $\mathrm{pH}_{\mathrm{pzc} 1}$ and $\mathrm{pH}_{\mathrm{pzc} 2}$ for this amorphous zeolite were 4.1 and 5.5, respectively. Figure 6 for illustration purposes contains error bars to indicate the measurement errors.

In general, it can be stated comparing the current zeta potential curves with those found in the literature for beta zeolite with different $\mathrm{Si} / \mathrm{Al}$ ratios [9] that no maxima were found in [9] and the curves typically decrease with increasing $\mathrm{pH}$.

\subsubsection{Effect of Temperature}

The effect of temperature on zeta potential for silica and alumina as well as for zeolites is shown in Figure 7. Zeta potential curves for $\gamma-\mathrm{Al}_{2} \mathrm{O}_{3}$ coincided and the point of zero charge for $\gamma-\mathrm{Al}_{2} \mathrm{O}_{3}$ has been constant (ca. 9.4) at all studied temperatures in the range $25-65^{\circ} \mathrm{C}$ (Figure 7a). The zeta potential behavior vs. $\mathrm{T}$ can be a sign than protonation/deprotonation steps have negligible temperature dependence in the case of alumina (Figure 7a) and, to a certain extent, silica (Figure 7b). More precisely, the zeta potential values decreased for silica with increasing temperature (Figure $7 \mathrm{~b})$ from $3.8\left(25^{\circ} \mathrm{C}\right)$ to $3.1\left(65^{\circ} \mathrm{C}\right)$.

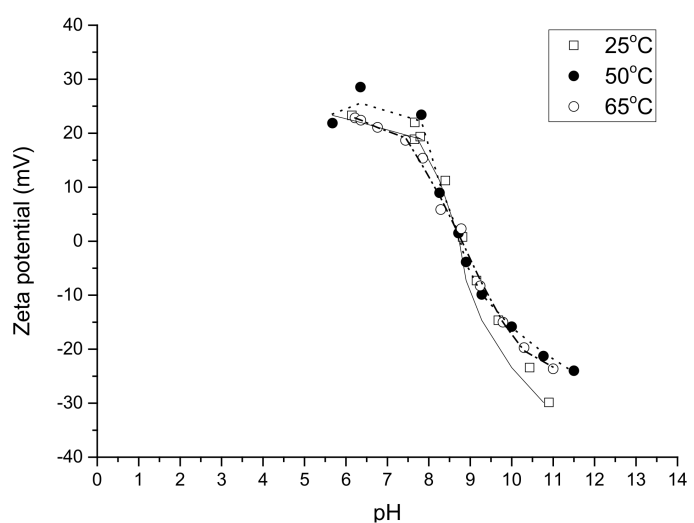

(a)

Figure 7. Cont. 


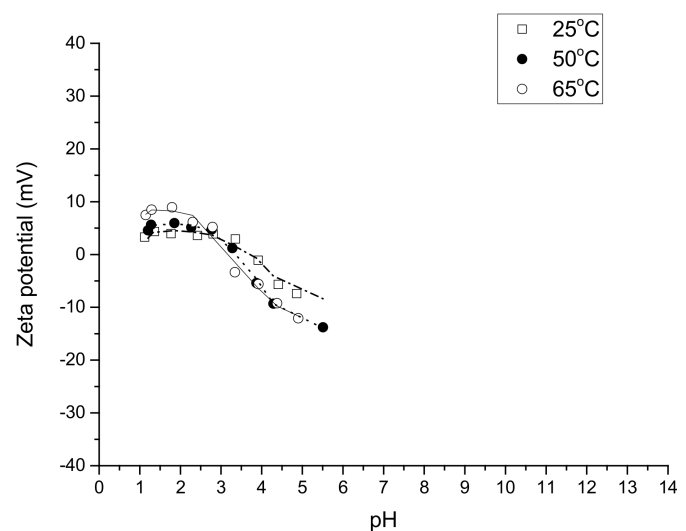

(b)

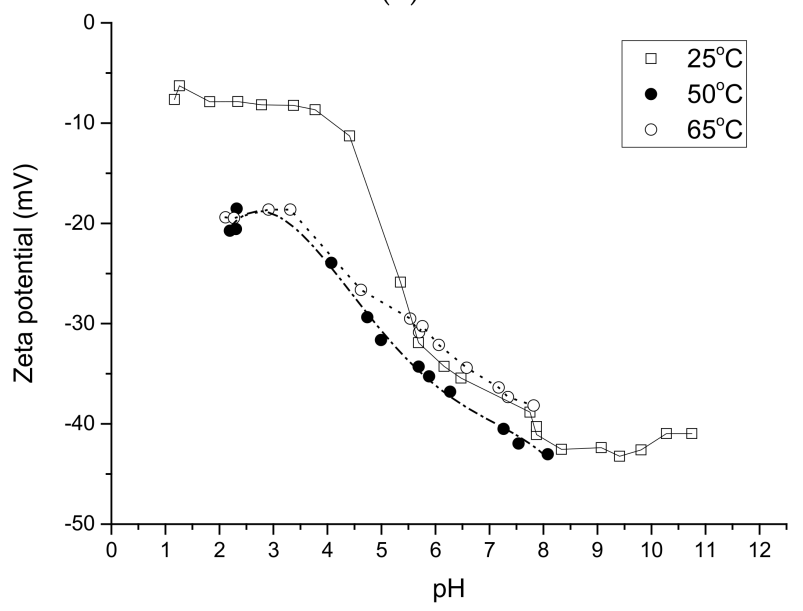

(c)

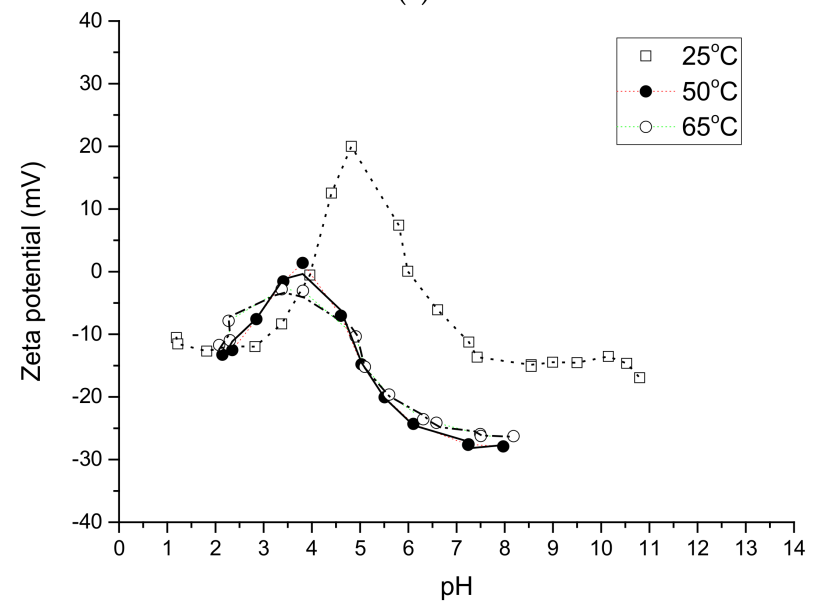

(d)

Figure 7. Effect of temperature on zeta potential for (a) alumina; (b) silica; (c) H-Beta-300; (d) H-Beta-25.

Conditions: $2 \mathrm{mg} / \mathrm{mL}$.

For zeolites the temperature effect was on the contrary very prominent (Figure 7c,d). Typically for H-beta-25 and H-beta-150 the maximum zeta potential values were the highest at $25^{\circ} \mathrm{C}$, whereas a larger decrease in the zeta potential values was observed at $50{ }^{\circ} \mathrm{C}$ and $65{ }^{\circ} \mathrm{C}$. These two curves are located, however, relatively close to each other, as can be seen also from the maxima zeta potential values given for each H-beta zeolite (Table 4). Not surprisingly the zeta potential curves for H-beta-300 resembled those of silica. The highest initial zeta potential values for this zeolite type were achieved at $25^{\circ} \mathrm{C}$. 
Table 4. Zeta potential values for beta zeolites.

\begin{tabular}{|c|c|c|c|c|c|}
\hline Material & Concentration $(\mathrm{mg} / \mathrm{mL})$ & $\mathrm{T}\left({ }^{\circ} \mathrm{C}\right)$ & Maximum Zeta Potential $(\mathrm{mV})$ at $\mathrm{pH}$ as ()$^{*}$ & IEP 1 * & IEP2 * \\
\hline \multirow{3}{*}{ H-beta-25 } & $2-4$ & 25 & $16(4.5)$ & 4.0 & 5.7 \\
\hline & $2-4$ & 50 & $0.7(3.9)$ & $3.7^{* *}$ & $4.0 * *$ \\
\hline & $2-4$ & 65 & $-3.7(3.7)$ & \multicolumn{2}{|c|}{ no } \\
\hline \multirow{2}{*}{ H-beta-150 } & $2-4$ & 25 & $14(4.7)$ & 4 & 5.7 \\
\hline & $2-4$ & 50 & $-3(3.9)$ & \multicolumn{2}{|c|}{ no } \\
\hline H-beta-150 & $2-4$ & 65 & $-4.8(3.6)$ & \multicolumn{2}{|c|}{ no } \\
\hline \multirow{3}{*}{ H-beta-300 } & $2-4$ & 25 & no & \multicolumn{2}{|c|}{ no } \\
\hline & $2-4$ & 50 & no & \multicolumn{2}{|c|}{ no } \\
\hline & $2-4$ & 65 & no & \multicolumn{2}{|c|}{ no } \\
\hline
\end{tabular}

* Average for concentrations $2-4 \mathrm{mg} / \mathrm{mL} ;{ }^{* *}$ These values correspond to concentration of $2 \mathrm{mg} / \mathrm{mL}$. No IEP were obtained for other concentrations.

From the discussion above it can be hypothesized that the $\mathrm{SiO}_{2} / \mathrm{Al}_{2} \mathrm{O}_{3}$ ratio reflecting the amount of aluminum in the framework can be an important parameter in determining zeta-potential behavior. This ratio affects acidity of $\mathrm{SiO}_{2} / \mathrm{Al}_{2} \mathrm{O}_{3}$ which increases with decreasing alumina content. An increase of silica to alumina ratio is also accompanied by a stronger influence of the silica phase.

The effect of the $\mathrm{SiO}_{2} / \mathrm{Al}_{2} \mathrm{O}_{3}$ ratio on zeta potential was, therefore, tested for $\mathrm{H}$-beta materials. The results show that for H-beta-25 and $\mathrm{H}$-beta-150, $\mathrm{pzc}_{1}$ was at $\mathrm{pH} 4$, whereas $\mathrm{pzc}_{2}$ for H-beta-150 and H-beta-25 was respectively at pH 5.7 and 6.0 (Figure 8). These two curves are relatively close to each other. It should be noted that almost the same values of isoelectric points $\left(\mathrm{pzc}_{1}\right.$ and $\mathrm{pzc}_{2}$ ) were obtained for H-beta-25 at salinity of 0.01 or $0.05 \mathrm{KCl}$ also with the maxima of zeta potential at pH 5 . Contrary the zeta potential curve for H-beta-300 resembled a simpler behavior of silica without any maxima. For beta zeolites there are reports showing both the maximum [33] and smooth behavior [9] in the zeta potential dependence on $\mathrm{pH}$.

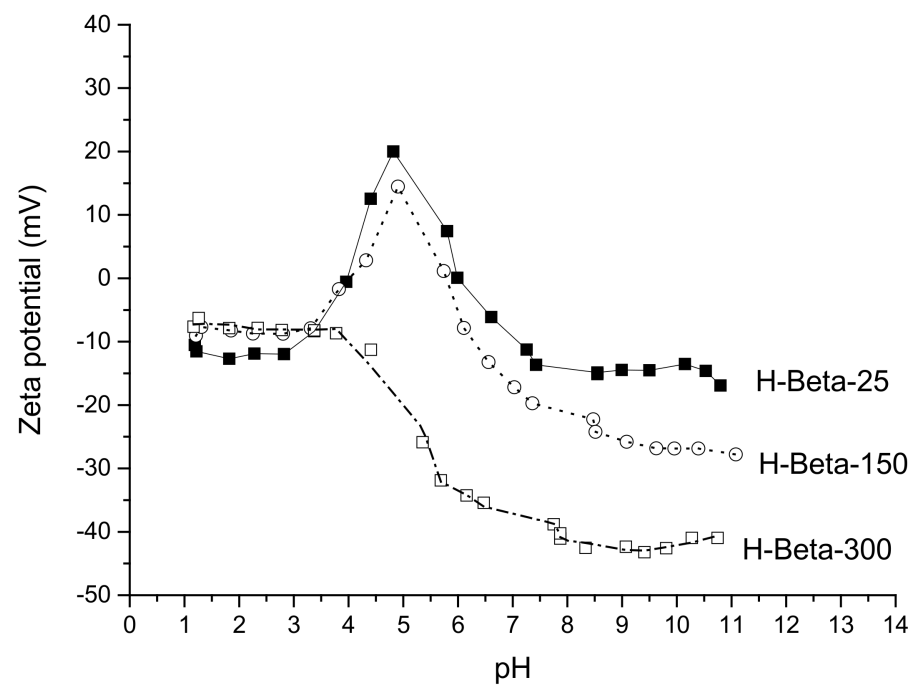

Figure 8. Zeta potential measurements of H-beta-25, H-beta-150 and H-beta-300 zeolite catalysts. Conditions: $2 \mathrm{mg} / \mathrm{mL}, 25^{\circ} \mathrm{C}$.

It was observed that for H-beta-25, H-beta- 150 and $\mathrm{H}-$ beta-300 zeolites, the zeta potential values were negative at $65^{\circ} \mathrm{C}$ clearly highlighting the influence of temperature on zeta potential because the values obtained at $25^{\circ} \mathrm{C}$ and $50^{\circ} \mathrm{C}$ were positive.

H-Beta-25 zeolite catalyst exhibited the highest zeta potential at $25^{\circ} \mathrm{C}$. The influence of acidity (i.e., Brønsted and Lewis acid sites) on zeta potential was studied using H-beta-150 zeolite with a lower amount of acid sites than in H-beta-25. Furthermore, H-beta- 150 at of $25^{\circ} \mathrm{C}$ exhibited a lower zeta potential 
than H-beta-25, clearly indicating that the presence of Brønsted and Lewis acid sites, their number and strength influenced the values of zeta potential. It is noteworthy to point out here that, besides the amount of $\mathrm{SiO}_{2}, \mathrm{Al}_{2} \mathrm{O}_{3}, \mathrm{SiO}_{2} / \mathrm{Al}_{2} \mathrm{O}_{3}$, also the presence of Brønsted and Lewis acid sites can also influence the values of zeta potential and isoelectric point (Table 4). The negative values of the surface charge in a broad range of $\mathrm{pH}$ values for beta zeolite have been previously reported [33].

\section{Discussion}

It follows from the experimental data that the initial zeta potential value decreased with decreasing $\mathrm{SiO}_{2} / \mathrm{Al}_{2} \mathrm{O}_{3}$ ratio at low $\mathrm{pH}$ (Figure 8), while for beta-zeolites the initial values were rather similar. The maximum zeta potential value for beta zeolite was the highest with the lowest $\mathrm{SiO}_{2} / \mathrm{Al}_{2} \mathrm{O}_{3}$ ratio and decreasing with increasing $\mathrm{SiO}_{2} / \mathrm{Al}_{2} \mathrm{O}_{3}$ ratio. As a comparison with the literature, a maximum value for the zeta potential at a certain $\mathrm{pH}$ has been reported for kaolinite in the presence of metal salts, whereas a declining trend of zeta potential as a function of $\mathrm{pH}$ was achieved in pure water [21]. Furthermore, a maximum of the zeta potential was found for muscovite at pH 4-5 [12] similarly as in the current case for H-beta-25 and H-beta- 150 at $25^{\circ} \mathrm{C}$. In the case of clay, the maximum in the zeta potential was higher, if the material had been aged at a low $\mathrm{pH}$ for a longer time. The complex behavior of zeta potential should be interpreted as done in [12] by taking into account partial dissolution of clay that occurred followed by adsorption of dissolved species at higher $\mathrm{pH}$ thus affecting the zeta potential values The structure of clays, however, differs from that of zeolites and thus it is difficult to relate their behavior in terms of the zeta potential curves.

For explanation of the complex behavior of zeta potential for zeolitic materials it should not be forgotten that the zeta potential and the values of surface charge represent some sort of lumped values and even for the case of the negative surface charge a negatively charged precursor can be deposited on the surface although in minor amounts [43]. Non-uniformity of surface sites in zeolites and thus presence of sites of different chemical nature and strength has been demonstrated by a range of techniques, including FTIR spectra of adsorbed pyridine [44], temperature programmed desorption of ammonia [45], or titration with bases [46]. Determination of acid sites in porous solid catalysts for the aqueous phase reactions using potentiometric titration method [47] showing several $\mathrm{pK}_{\mathrm{a}}$ values. Presence of different sites and as a consequence utilization of non-Langmurian adsorption isotherms [47,48] while resulting in deviations of a classical Nernstian behavior, cannot, however, explain an increase of zeta potential or maxima with an increase of $\mathrm{pH}$.

A more feasible explanation was advanced by Nosrati et al. [12], who noticed an increase of zeta potential with a $\mathrm{pH}$ increase from 3 to ca. 4.5 in the case of muscovite suspensions and a subsequent decrease above the latter value. Such behavior can be ascribed to leaching of multivalent metal ions (Al(III)), subsequent hydrolysis and specific adsorption and precipitation onto the solid surfaces. In addition to liberation of $\mathrm{Al}(\mathrm{III})$ and its subsequent contribution to the positive charge of the surface after readsorption, $\mathrm{Al}(\mathrm{III})$ at higher concentrations can also contribute to ionic strength. Qualitative description of the zeta potential behavior in the case of zeolites should thus take into account $\mathrm{pH}$ dependent speciation changes and leaching of alumina species. In fact, stability of zeolites at low $\mathrm{pH}$ has been elucidated in the literature. In particular, for acid leached beta zeolites it was shown in [49] that the ratio of $\mathrm{Si} / \mathrm{Al}$ ratio increases with the severity of the treatment because both framework and extra-framework $\mathrm{Al}$ atoms are progressively leached from the zeolite.

Changes in the ionic strength of the solution during measurements can also happen because of ion exchange with alkali ions present even in the proton forms of commercial zeolites. In the current work, however, the ammonium forms were used for catalyst preparation, thus presence of alkali atoms did not influence the observed zeta potential behavior.

In general, experimental data presented above clearly demonstrate a very complex behavior of zeta potential for the studied materials. The current work was aimed at collection of reliable experimental data for zeolitic materials with different structure and acidity rather than providing a detailed theoretical explanation for the observed behavior. From the phenomenological observations, it became clear that in 
the case of zeolites the developed surface charge or zeta potential cannot be predicted as an additive value for silica and alumina zeta potentials corrected for the corresponding $\mathrm{SiO}_{2} / \mathrm{Al}_{2} \mathrm{O}_{3}$ ratio. This in practice implies that for preparation of supported catalysts by, for example, depositing a metal containing precursor by adsorption, a certain procedure operative for one type of zeolite with a particular acidity might not be valid for other materials. Metal deposition should be done in a way that the metal precursor will not be repelled from the surface. Zeta potential measurements performed in the current work clearly showed that the silica-to-alumina ratio, zeolite type, as well as temperature significantly influence the values of zeta potential, while concentration of solids in the slurry in the studied range of concentrations was less important.

Similar statements can be also made regarding catalyst shaping when the surface charge should be taken into account while developing experimental procedures for forming catalyst granules by e.g., extrusion. It can be at the same time argued how relevant are zeta potential measurements for catalyst shaping, in particular, extrusion occurring in high density suspensions. For example, the work of Kraushaar-Czarnetzki and co-workers, showing a possibility to control the aggregation and peptization of zeolites [6], was done in diluted suspensions. Repulsive interparticle forces induced from the electrostatic double layer can be accurately described by DLVO theory accounting for colloidal interactions between charged particles [50]. Zeta potential and the isoelectric point are thus relevant in describing the charge on the particle surface. In the case of suspensions with high concentration of solids, other types of adhesion forces especially in the presence of polymeric binders might be of more relevance.

\section{Materials and Methods}

\subsection{Catalytic Materials}

Several different commercial $\mathrm{NH}_{4}$-zeolites purchased from Zeolyst International (Conshohocken, Pensylvania, USA) with varying $\mathrm{SiO}_{2} / \mathrm{Al}_{2} \mathrm{O}_{3}$ ratio were used in this work, such as $\mathrm{NH}_{4}-$ beta-25, $\mathrm{NH}_{4}$-beta-150 and $\mathrm{NH}_{4}$-beta-300. The last number in the zeolite labels denotes $\mathrm{SiO}_{2}$ to $\mathrm{Al}_{2} \mathrm{O}_{3}$ ratio. The $\mathrm{NH}_{4}$-zeolites were calcined using a stepwise temperature program: $25-250{ }^{\circ} \mathrm{C}(40 \mathrm{~min})-400{ }^{\circ} \mathrm{C}(140 \mathrm{~min})$ resulting in the proton form of zeolites. All materials were sieved below $32 \mu \mathrm{m}$ fraction. Vista as well as silica gel Si-60 from Merck (Darmstadt. Germany) and fumed silica (Aldrich, Espoo, Finland) were applied. $\mathrm{Al}_{2} \mathrm{O}_{3}$ (Versal alumina GL25) was purchased from La Roche (Welwyn Garden City, UK). In addition, a material exhibiting an amorphous structure using a synthesis time of $24 \mathrm{~h}$ was prepared following the procedure described in [51] for comparison. It was denoted as Beta-22.

\subsection{Characterization Methods}

Prior to the zeta potential measurements, the supports: $\mathrm{Al}_{2} \mathrm{O}_{3}, \mathrm{SiO}_{2}$, and H-beta-25, H-beta-150, H-beta-300 zeolites were characterized using X-ray powder diffraction (XRD) for phase purity and structure, scanning electron microscopy (SEM) for morphology, nitrogen physisorption for specific surface area, particle morphology and periodicity. FTIR using pyridine as a probe molecule was performed to elucidate presence, strength and amount of Brønsted and Lewis acid sites. Elemental analysis was carried out using energy dispersive X-ray (EDAX) micro-analysis.

Pyridine (>99.5\%) adsorption-desorption was studied using an ATI Mattson FTIR (LabX, Midland, $\mathrm{ON}$, Canada). Self-supported wafers with the weight of 15-20 mg were prepared. Pyridine was adsorbed at $100{ }^{\circ} \mathrm{C}$ for $30 \mathrm{~min}$. Thereafter a sample was evacuated at three different temperatures of $250{ }^{\circ} \mathrm{C}, 350{ }^{\circ} \mathrm{C}$, and $450{ }^{\circ} \mathrm{C}$. Spectra were recorded in vacuum with a spectral resolution of $2 \mathrm{~cm}^{-1}$. Spectral bands at $1540 \mathrm{~cm}^{-1}$ and $1450 \mathrm{~cm}^{-1}$ were used to identify Brønsted and Lewis acid sites. For the quantitative analysis, the extinction coefficients of Emeis [52] were applied.

Solid state ${ }^{27}$ Al-NMR spectra of H-beta-25, H-beta-150, H-beta-300 zeolite catalysts were used to analyse the location of aluminum species in the framework and extra framework positions. 
Single pulse excitation spectra were recorded on an AVANCE III-800 spectrometer (Bruker, Germany) in 18.8 T magnetic field ( ${ }^{27} \mathrm{Al}$ resonance frequency $208.4 \mathrm{MHz}$ ) using a Bruker MAS probe for $3.2 \mathrm{~mm}$ on zirconia rotors. The spinning speed of the samples was $22.0 \mathrm{kHz}$ in all the experiments. To keep quantitative intensities $10^{\circ}$ short excitation pulses were used at rf field strength $50 \mathrm{kHz}$ and $0.1 \mathrm{~s}$ relaxation delay between the accumulations. Intensity has been normalized by dividing the absolute intensity by the mass of a sample and by a number of scans. The spectra were referenced to the resonance frequency of $\mathrm{KAl}\left(\mathrm{SiO}_{4}\right)_{2} \cdot 12 \mathrm{H}_{2} \mathrm{O}$.

\subsection{Zeta Potential Measurements}

The zeta potential measurements were performed with a Zetasizer Nano ZS (Malvern Instruments, Malvern, United Kingdom) using light scattering technique while for $\mathrm{pH}$ measurements the potentiometric method (MPT-2) was applied. The sample concentration was varied from 2 to $4 \mathrm{mg} / \mathrm{mL}$ suspended in de-ionized water. In the majority of measurements $\mathrm{NaOH}$ and $\mathrm{HCl}$ were used as titrants with no addition of indifferent electrolytes. In some measurements $\mathrm{KCl}$ was applied to change the ionic strength. Zeta potential was measured in the temperature range of $25-65^{\circ} \mathrm{C}$, and each measurement was repeated three times. The final zeta potential vs. $\mathrm{pH}$ curves were averaged from three measurements. Few tests were initially done using an equilibration procedure keeping the suspension for $24 \mathrm{~h}$ prior to measurements. Since no big differences were seen between this procedure and an accelerated one the majority of measurements were done with the latter approach. In essence, each time when a suspension was prepared the measurements started few minutes after that. The measurement time covering the whole $\mathrm{pH}$ range typically took one hour or slightly more depending on the sample. The Smoluchowsky theory was applied in determination of the zeta-potential.

\section{Conclusions}

A systematic investigation of zeta potential as a function of solution $\mathrm{pH}$ was made in the current work for $\mathrm{H}$ forms of beta zeolites exhibiting three different $\mathrm{SiO}_{2} / \mathrm{Al}_{2} \mathrm{O}_{3}$ ratios. The zeta potentials curves were measured in the $25-65^{\circ} \mathrm{C}$ interval using silica and alumina as reference materials. To get statistically and physically reliable results, zeta potential was measured three times at every $\mathrm{pH}$ for the same sample altering also the concentration of solids in the slurry. Preliminary experiments showed a good agreement with the literature data published for alumina and silica.

The results for zeta potential measurements for $\mathrm{H}$-beta zeolites showed that higher temperature of the solution decreased the zeta potential. Typically, there were maxima of the zeta potential values for highly acidic $\mathrm{H}$-beta at a certain $\mathrm{pH}$, not reported previously in the literature. For two zeolites, exhibiting the lowest $\mathrm{Si} / \mathrm{Al}$ ratios, namely H-beta- 25 and H-beta-150, the zeta potential curves were quite close to each other. These materials had also similar acidity. On the other hand, for low acidic H-beta-300 the zeta potential values were negative, while the shape of the zeta potential curve resembled that of silica and alumina.

Thus, there are several factors affecting the electrophoretic behavior of zeolites. An increase in alumina content leads to decreasing acidity (mobility) of bridging protons, but the number of acidic sites increases; therefore, zeta potential becomes a non-monotonic function of $\mathrm{pH}$. Particle and pore sizes, $\mathrm{S}_{\mathrm{BET}}$ value influence the amount of the bound water possessing lower activity as a solvent that can affect the mobility of protons and the structure of the electric double layer (EDL), i.e., zeta potential value. In other words, at the same structure of a surface in pores and at a surface of nano- and microparticles, the EDL structure should be different. External factors ( $\mathrm{T}$, content, $\mathrm{pH}$ ) can differently affect the EDL structure in pores of different sizes or at surface of particles of different sizes.

Acknowledgments: I.H. was supported by the Estonian Research Agency and the European Regional Development Fund project TK134.

Author Contributions: D.M. and T.S. conceived and designed the experiments; N.K. synthesized catalysts, X.L., A.A. and Z.V. performed the zeta potential measurements and zeolites characterization, K.E: contributed to zeta 
potential measurements. I.H. contributed to NMR characterization; V.M.G. analyzed the data; P.M.-A. and D.M. wrote the paper.

Conflicts of Interest: The authors declare no conflict of interest.

\section{References}

1. Mäki-Arvela, P.; Murzin, D.Y. Effect of catalyst synthesis parameters on the metal particle size. Appl. Catal. A Gen. 2013, 451, 251-281. [CrossRef]

2. Murzin, D.Y.; Simakova, O.A.; Simakova, I.L.; Parmon, V.N. Thermodynamic analysis of the cluster size evolution in catalyst preparation by deposition precipitation. React. Kinet. Mech. Catal. 2011, 104, 259-266. [CrossRef]

3. Zacahua-Tlacuatl, G.; Pérez-González, J.; Castro-Arellano, J.J.; Balmori-Ramírez, H. Rheological characterization and extrusion of suspensions of natural zeolites. Appl. Rheol. 2010, 20, 1.

4. Zhou, Z.; Scales, P.J.; Boger, D.V. Chemical and physical control of the rheology of concentrated metal oxide suspensions. Chem. Eng. Sci. 2001, 56, 2901-2920. [CrossRef]

5. Foundas, M.; Britcher, L.G.; Fornasiero, D.; Morris, G.E. Boehmite suspension behaviour upon adsorption of methacrylate-phosphonate copolymers. Powder Technol. 2015, 269, 385-391. [CrossRef]

6. Mäurer, T.; Muller, S.P.; Kraushaar-Czarnetzki, B. Aggregation and peptization of zeolite crystals in sols and suspensions. Ind. Eng. Chem. Res. 2001, 40, 2573-2579. [CrossRef]

7. Devyatkov, S.Y.; Zinnurova, A.; Aho, A.; Kronlund, D.; Peltonen, J.; Kuzichkin, N.V.; Lisitsyn, N.V.; Murzin, D.Y. Shaping of sulfated zirconia catalysts by extrusion: Understanding the role of binders. Ind. Eng. Chem. Res. 2016, 55, 6595-6606. [CrossRef]

8. Soled, S.; Wachter, W.; Wo, H. Use of zeta potential measurements in catalyst preparation. Stud. Surf. Sci. Catal. 2010, 175, 101-107.

9. Yang, W.; Wang, X.; Tang, Y.; Wang, Y.; Ke, C.; Fu, S. Layer-by-layer assembly of nanozeolite based on polymeric microsphere: Zeolite coated sphere and hollow zeolite spinel. J. Macromol. Sci. Pure Appl. Chem. A 2002, 39, 509-526. [CrossRef]

10. Adamczyk, Z.; Nattich, M.; Wasilewska, M. Irreversible adsorption of latex particles on fibrinogen covered mica. Adsorption 2010, 16, 259-269. [CrossRef]

11. Nishimura, S.; Scales, P.J.; Tateyama, H.; Tsunematsu, K.; Healy, T.W. Molecular-scale structure of the cation modified muscovite mica basal plane. Langmuir 1995, 11, 291. [CrossRef]

12. Nosrati, J.; Addai-Mensah, W.; Skinner, W. pH-mediated interfacial chemistry and particle interactions in aqueous muscovite dispersions. Chem. Eng. J. 2009, 152, 406-414. [CrossRef]

13. Zhuang, J.; Yu, G.R. Effects of surface coatings on electrochemical properties and contaminant sorption of clay minerals. Chemosphere 2002, 49, 619-628. [CrossRef]

14. Yalcinkaya, E.E.; Guler, C. Electrokinetic properties of acid-activated montmorillonite dispersions. Sep. Sci. Technol. 2010, 45, 635-642. [CrossRef]

15. Rozalen, M.; Brady, P.V.; Huertas, F.J. Surface chemistry of K-montmorillonite: Ionic strength, temperature dependence and dissolution kinetics. J. Colloid Interface Sci. 2009, 333, 474-484. [CrossRef] [PubMed]

16. Kuzniatsova, T.; Kim, Y.; Shqau, K.; Dutta, P.K.; Verweif, H. Zeta potential measurements of zeolite Y: Application in homogeneous deposition of particle coatings. Microporous Mesoporous Mater. 2007, 103, 102-107. [CrossRef]

17. Nikolakis, V. Understanding interactions in zeolite colloidal suspensions: A review. Curr. Opin. Colloid Interface Sci. 2005, 10, 203-210. [CrossRef]

18. Mekhamer, W.K. The colloidal stability of raw bentonite deformed mechanically by ultrasound. J. Saudi Chem. Soc. 2010, 14, 301-306. [CrossRef]

19. Alvarez-Silva, M.; Mirnezami, M.; Uribe-Salas, A.; Finch, J.A. The point of zero charge of phyllosilicate minerals using the Mular-Roberts titration technique. Min. Eng. 2010, 23, 383-389. [CrossRef]

20. Yukselen, Y.; Kaya, A. Zeta potential of kaolinite in the presence of alkali, alkaline earth and hydrolyzable metal ions. Water Air Soil Pollut. 2003, 145, 155-168. [CrossRef]

21. Yukselen-Aksoy, Y.; Kaya, A. A study of factors affecting on the zeta potential of kaolinite and quartz powder. Environ. Earth Sci. 2011, 62, 697-705. [CrossRef]

22. Chassagne, C.; Mietta, F.; Winterwerp, J.C. Electrokinetic study of kaolinite suspensions. J. Colloid Interface Sci. 2010, 336, 352-359. [CrossRef] [PubMed] 
23. Erzin, Y.; Yukselen, Y. The use of neural networks for the prediction of zeta potential of kaolinite. Math. Geosci. 2009, 41, 779-797. [CrossRef]

24. Dzenitis, J.M. Soil chemistry effects and flow prediction in electroremediation of soil. Environ. Sci. Technol. 1997, 31, 1191-1197. [CrossRef]

25. Erdemoglu, M. Zeta potential of pyrophyllite in aqueous solutions of alkaline and alkaline earth metal cations and low-molecular-weight organic anions. J. Dispers. Sci. Technol. 2007, 28, 689-695. [CrossRef]

26. Kursun, I. Determination of flocculation and adsorption desorption characteristics of Na-feldspar concentrate in the presence of different polymers. Physicochem. Probl. Min. Process. 2010, 44, 127-142.

27. Cao, E.; Bryant, R.; Williams, D.J.A. Electrochemical properties of Na-attapulgite. J. Colloid Interface Sci. 1996, 179, 143-150. [CrossRef]

28. Heath, D.; Tadros, T.F. Influence of $\mathrm{pH}$, electrolyte, and poly(vinyl alcohol) addition on the rheological characteristics of aqueous dispersions of sodium montmorillonite. J. Colloid Interface Sci. 1983, 93, 307-319. [CrossRef]

29. Neaman, A.; Singer, A. Rheological properties of aqueous suspensions of palygorskite. Soil Sci. Soc. Am J. 2000, 64, 427. [CrossRef]

30. Mockoviciakova, A.M.; Orolinova, Z.; Skvarla, J. Enhancement of the bentonite sorption properties. J. Hazard. Mater. 2010, 180, 274-281. [CrossRef] [PubMed]

31. Stathi, P.; Papadas, I.T.; Enotiadis, A.; Gengler, R.Y.N.; Gournis, D.; Rudolf, P.; Deligiannakis, Y. Effects of acetate on cation exchange capacity of a Zn-containing montmorillonite: Physicochemical significance and metal uptake. Langmuir 2009, 25, 6825-6833. [CrossRef] [PubMed]

32. Valdés, H.; Tardón, R.F; Zaror, C.A. Role of surface hydroxyl groups of acid-treated natural zeolite on the heterogeneous catalytic ozonation of methylene blue contaminated water. Chem. Eng. J. 2012, 211-212, 388-395. [CrossRef]

33. Magriotis, Z.M.; Leal, P.V.B.; de Sales, P.F.; Papini, R.M.; Viana, P.R.M.; Arroyo, P.A. A comparative study for the removal of mining wastewater by kaolinite, activated carbon and beta zeolite. Appl. Clay Sci. 2014, 91-92, 55-62. [CrossRef]

34. Gunko, V.M.; Zarko, V.I.; Leboda, R.; Chibowski, E. Aqueous suspension of fumed oxides: Particle size distribution and zeta potential. Adv. Colloid Interface Sci. 2001, 91, 1-112. [CrossRef]

35. Wang, N.; Hsu, C.; Tseng, S.; Hsu, J.-P. Influence of metal oxide nanoparticles concentration on their zeta potential. J. Colloid Interface Sci. 2013, 407, 22-28. [CrossRef] [PubMed]

36. Guo, W.; Xionh, C.; Huang, L.; Li, Q. Synthesis and characterization of composite molecular sieves comprising zeolite Beta with MCM-41 structures. J. Mater. Chem. 2001, 11, 1886-1890. [CrossRef]

37. Torozova, A.; Mäki-Arvela, P.; Aho, A.; Kumar, N.; Smeds, A.; Peurla, M.; Sjöholm, R.; Heinmaa, I.; Korchagina, D.V.; Volcho, K.P.; et al. Heterogeneous catalysis for transformation of biomass derived compounds beyond fuels: Synthesis of monoterpenoid dioxinols with analgesic activity. J. Mol. Catal. A. Chem. 2015, 397, 48-55. [CrossRef]

38. Schmidt, S.A.; Kumar, N.; Shchukarev, A.; Eränen, K.; Mikkola, J.-P.; Murzin, D.Y.; Salmi, T. Preparation and characterization of neat and $\mathrm{ZnCl}_{2}$ modified zeolites and alumina for methyl chloride synthesis. Appl. Catal. A Gen. 2013, 468, 120-134. [CrossRef]

39. Aho, A.; Kumar, N.; Eränen, K.; Salmi, T.; Hupa, M.; Murzin, D.Y. Catalytic pyrolysis of biomass in a fluidized bed reactor: Influence of the acidity of H-beta zeolite. Proc. Saf. Environ. Prot. 2007, 85, 473-480. [CrossRef]

40. Li, S.; Zheng, A.; Su, Y.; Fang, H.; Shen, W.; Yu, Z.; Chen, L.; Deng, F. Extra-framework aluminium species in hydrated faujasite zeolite as investigated by two-dimensional solid-state NMR spectroscopy and theoretical calculations. Phys. Chem. Chem. Phys. 2010, 12, 3895-3903. [CrossRef] [PubMed]

41. Murzin, D. Engineering Catalysis; De Gryuter: Berlin, Germany, 2013; Volume 364.

42. Junior, J.A.A.; Baldo, J.B. The behavior of Zeta potential of silica suspensions. New J. Glass Ceram. 2014, 4, 29. [CrossRef]

43. Hesse, B.; Gläsel, J.; Kern, A.M.; Murzin, D.Y.; Etzold, B.J.M. Preparation of carbide-derived carbon supported platinum catalysts. Catal. Today 2015, 249, 30-37. [CrossRef]

44. Kubicka, D.; Kumar, N.; Venäläinen, T.; Karhu, H.; Kubickova, I.; Österholm, H.; Murzin, D.Y. Metal-support interactions in zeolite-supported noble metals: Influence of metal crystallites on the support acidity. J. Phys. Chem. B 2006, 110, 4937-4946. [CrossRef] [PubMed] 
45. Niwa, M.; Katada, N. Measurements of acidic property of zeolites by temperature programmed desorption of ammonia. Catal. Surv. Asia 1997, 1, 215-226. [CrossRef]

46. Yu, K.; Kumar, N.; Aho, A.; Roine, J.; Heinmaa, I.; Murzin, D.Y.; Ivaska, A. Determination of acid sites in porous aluminosilicate solid catalysts for aqueous phase reactions using potentiometric titration method. J. Catal. 2016, 335, 117-124. [CrossRef]

47. Zarzycki, R.; Charmas, R.; Szabelski, P. Study of proton adsorption at heterogeneous oxide/electrolyte interface. Prediction of the surface potential using Monte Carlo simulations and 1-pK approach. J. Comput. Chem. 2004, 25, 704-711. [CrossRef] [PubMed]

48. Zarzycki, R.; Szabelski, P.; Piasecki, W. Modelling of $\zeta$-potential of the montmorillonite/electrolyte solution interface. Appl. Surf. Sci. 2007, 253, 5791-5796. [CrossRef]

49. Yonli, A.H.; Gener, I.; Mignard, S. Influence of post-synthesis treatment on BEA zeolites hydrophobicity assessed under static and dynamic conditions. Microporous Mesoporous Mater. 2009, 122, 135-142. [CrossRef]

50. Akhtar, F.; Andersson, L.; Oqunwumi, S.; Hedin, N.; Bergström, L. Structuring adsorbents and catalysts by processing of porous powders. J. Eur. Ceram. Soc. 2014, 34, 1643-1666. [CrossRef]

51. Villegas, J.I.; Kumar, N.; Heikkilä, T.; Lehto, V.-P.; Salmi, T.; Murzin, D.Y. A study on the dimerization of 1-butene over Beta zeolite. Top. Catal. 2007, 45, 187-190. [CrossRef]

52. Emeis, C.A. Determination of integrated molar extinction coefficients for infrared absorption bands of pyridine adsorbed on solid acid catalysts. J. Catal. 1993, 141, 347-354. [CrossRef]

Sample Availability: Samples of the compounds are available from the authors.

(C) 2018 by the authors. Licensee MDPI, Basel, Switzerland. This article is an open access article distributed under the terms and conditions of the Creative Commons Attribution (CC BY) license (http://creativecommons.org/licenses/by/4.0/). 